Article

\title{
Optimization of the Adhesion Strength of Arc Ion Plating TiAlN Films by the Taguchi Method
}

\section{Yun-Kon Joo, Shi-Hong Zhang *, Jae-Hong Yoon and Tong-Yul Cho}

School of Nano \& Advanced Materials Engineering, Changwon National University, Changwon, 641-773, Korea; E-Mails: ykjoo@changwon.ac.kr (Y.-K.J.); jhyoon@changwon.ac.kr (J.-H.Y.); tycho@changwon.ac.kr (T.-Y.C.)

* Author to whom correspondence should be addressed; E-Mail: zsh10110903@hotmail.com; Tel. +82-55-283-7532; Fax: +82-55-283-7532

Received: 7 June 2009 / Accepted: 17 June 2009 / Published: 17 June 2009

\begin{abstract}
A three-level six-factor (arc power, substrate temperature, pre-treatment bias voltage, working pressure, deposition bias voltage and pretreatment time) orthogonal experimental array (L18) to optimize the adhesion strength of arc ion plating (AIP) TiAIN films was designed using the Taguchi method. An optimized film process, namely substrate temperature $220{ }^{\circ} \mathrm{C}$, arc power $60 \mathrm{~A}$, negative bias voltage $-800 \mathrm{~V}$, nitrogen pressure $10^{-2}$ Torr, pretreated voltage $-450 \mathrm{~V}$ and pretreated time 15 minutes was obtained by the Taguchi program for the purpose of obtaining a larger critical load. The critical load of the optimized TiAlN film $(53 \mathrm{~N})$ was increased by $43 \%$ compared to the film with the highest critical load before optimization. The improvement in the adhesion strength of the films was attributed to the enhancement of hardness and the competitive growth of the (111), (200) and (220) orientations in the film.
\end{abstract}

Keywords: arc ion plating; TiAlN; adhesion strength; Taguchi method

\section{Introduction}

Arc ion plating (AIP) has been widely used as a hard coating technique because of its many advantages such as high ionization, high deposition rate and strong adhesion between films and 
substrates [1,2]. Plasma surface engineering hard coating methods have been used to solve wear and tribology problems in various industrial areas during the past decades. AIP TiN coating is widely used in cutting tool applications because of its high hardness, high adhesion strength and low friction coefficient. Although TiN coating has excellent mechanical properties, it cannot be used at high temperatures because of its poor thermal and chemical stability. In recent years TiAlN films have drawn attention since addition of $\mathrm{Al}$ to $\mathrm{TiN}$ enhances its anti-oxidation behavior and improves the micro hardness in comparison with TiN films alone [3-5]. A third element can be incorporated into binary system to improve the coating properties. Even though other coatings are present on the market today, TiAlN is still used in a wide range of industries. In all these applications, a crucial factor for the durability and the performance of the coated components is the adhesion of the coating on the substrate.

It has not yet been explored whether adhesion strength can be enhanced by adjusting the deposition conditions, i.e. arc power, substrate temperature, pretreatment voltage, working pressure, deposition bias voltage and pre-treatment time. In view of the demands of fast product manufacturing, engineers have to quickly find an optimal recipe for processing, so a lesser number of experiments are desired. The Taguchi method was introduced as a useful engineering methodology to find optimized process conditions with a small number of experiments. For example, a complete array of a 6 factors with 3 levels required 729 (36) runs. By selecting a proper orthogonal array by the Taguchi method, the study of 6 factors with 3 levels as mentioned above can be conducted with only 18 experimental runs [6,7]. To evaluate the rank of each factor, the deltas of the means of each level of the six factors of arc power, substrate temperature, pretreatment voltage, working pressure, deposition bias voltage and pretreatment time were calculated and then greater delta values were considered as major influences for the experiment. Percentages representing the contribution of the experimental variations for each factor are determined by so-called ANOVA analysis. The Taguchi method is a useful engineering methodology to find a correlation between control factors and product characteristics [8].

The aim of this work was to study the adhesion strength of TiAlN films designed using the Taguchi method. Most of the literature only mentions the mechanical damage or wear-resistance effects on TiAlN films $[9,10]$, but an obstacle to the wide applicability of TiAlN film is associated with poor adhesion to the substrate due to high residual stress inherent in the films, especially under hightemperature working condition. In the previous studies, most of researchers were mainly concerned with the improvement of the adhesion strength of the films with steel tools by the introduction of gradient layers or multilayers $[11,12]$. In this investigation, TiAlN films were investigated by scratch tester, X-ray diffraction, SEM, Nanoindentor analysis. The objective of this study was to explore and determine how to optimize of the control factors in order to achieve the best adhesion strength for future product requirements.

\section{Experimental Section}

The Taguchi method is known to be a very good tool for parameter study and was applied in the present work. This method is powerful and effective in helping manufacturers design their products and processes as well as to solve troublesome quality problems. After using Taguchi analysis, the factorial effect and contribution ratio of each factor on each property were presented. In this study, TiAlN films were coated by AIP technique on an SKD61 hardened substrate $(0.32 \sim 0.42 \%$ C, 
$0.8 \sim 1.2 \% \mathrm{Si}, 0.50 \% \mathrm{Mn}, 4.50 \sim 5.50 \% \mathrm{Cr}, 1.00 \sim 1.50 \% \mathrm{Mo}, 0.8 \sim 1.2 \% \mathrm{~V}, 0.03 \mathrm{~S}, 0.03 \% \mathrm{P}$ and $89.7 \sim 91.9 \% \mathrm{Fe}$ ) which was polished with a $1 \mu \mathrm{m}$ polishing disc to get mirror surface plates for the coating, using the following control factors: 1) are arc power $\left(\mathrm{I}_{\mathrm{arc}}\right) 12$ 2) temperature of substrate $\left(\mathrm{T}_{\text {sub }}\right) 13$ ) pre-sputtering voltage $\left(\mathrm{V}_{\mathrm{p}}\right) 1$ 4) working gas pressure $\left.(\mathrm{P}) 15\right)$ deposition bias voltage $\left(\mathrm{V}_{\text {bias }}\right) 1$ and 6) pre-sputtering time $\left(\mathrm{t}_{\mathrm{p}}\right)$, respectively. In addition, the base pressure in this work was fixed at $9.0 \times 10^{-6}$ torr. The key parameters using the six-factor with three-level (L18) orthogonal array of experimental arrangements was listed in Table 1 and 2. This AIP system (Figure 1) consisted of one symmetric target. The substrates were located at center of the vacuum chamber, which could be rotated during operation. The target had $\mathrm{Ti} / \mathrm{Al}$ atomic ratio of 50/50.

Table 1. Taguchi L18 experimental design: Variables.

\begin{tabular}{lccc}
\hline \multirow{2}{*}{ Variable } & \multicolumn{3}{c}{ Design number } \\
\cline { 2 - 4 } & $\mathbf{1}$ & $\mathbf{2}$ & $\mathbf{3}$ \\
\hline A: Temperature of substrate $\left({ }^{\circ} \mathrm{C}\right)$ & 220 & 320 & 420 \\
B: Arc current (A) & 60 & 80 & 100 \\
C: Bias voltage (V) & -100 & -450 & -800 \\
D: Working pressure (torr) & $5 \times 10^{-1}$ & $5 \times 10^{-2}$ & $5 \times 10^{-3}$ \\
E: Pre-treatment voltage (V) & -100 & -450 & -800 \\
F: Pre-treatment time (minute) & 5 & 10 & 15 \\
\hline
\end{tabular}

Table 2. Taguchi L18 experimental design: Design number.

\begin{tabular}{ccccccc}
\hline \multirow{2}{*}{ Sample No. } & \multicolumn{7}{c}{ Variable } \\
\cline { 2 - 7 } & A & B & C & D & E & F \\
\hline 1 & 1 & 1 & 1 & 1 & 1 & 1 \\
2 & 1 & 2 & 2 & 2 & 2 & 2 \\
3 & 1 & 3 & 3 & 3 & 3 & 3 \\
4 & 2 & 1 & 1 & 2 & 2 & 3 \\
5 & 2 & 2 & 2 & 3 & 3 & 1 \\
6 & 2 & 3 & 3 & 1 & 1 & 2 \\
7 & 3 & 1 & 2 & 1 & 3 & 2 \\
8 & 3 & 2 & 3 & 2 & 1 & 3 \\
9 & 3 & 3 & 1 & 3 & 2 & 1 \\
10 & 1 & 1 & 3 & 3 & 2 & 2 \\
11 & 1 & 2 & 1 & 1 & 3 & 3 \\
12 & 1 & 3 & 2 & 2 & 1 & 1 \\
13 & 2 & 1 & 2 & 3 & 1 & 3 \\
14 & 2 & 2 & 3 & 1 & 2 & 1 \\
15 & 2 & 3 & 1 & 2 & 3 & 2 \\
16 & 3 & 1 & 3 & 2 & 3 & 1 \\
17 & 3 & 2 & 1 & 3 & 1 & 2 \\
18 & 3 & 3 & 2 & 1 & 2 & 3 \\
\hline
\end{tabular}

The crystal structures of the coatings were characterized by XRD. The surface morphology and cross-section image of the coatings were observed by SEM. The hardness of TiAlN films was 
measured via a $20 \mathrm{mN}$ nano-indentation tester. The adhesion strength between films and substrates was obtained with a linear scratch tester (RST S/N: 27-0510). The scratch adhesion test was performed with a spherically tipped diamond indenter $\left(120^{\circ}\right.$ cone, $200 \mu \mathrm{m}$ radius spherical tip) by continuously increasing the load with a normal force from 1 to $50 \mathrm{~N}$, with a loading rate of $50 \mathrm{~N} /$ minutes and a transverse velocity of the sample of $5 \mathrm{~mm} / \mathrm{min}$. The length of the scratch track was $5 \mathrm{~mm}$.

Figure 1. Schematic diagram of the AIP system.

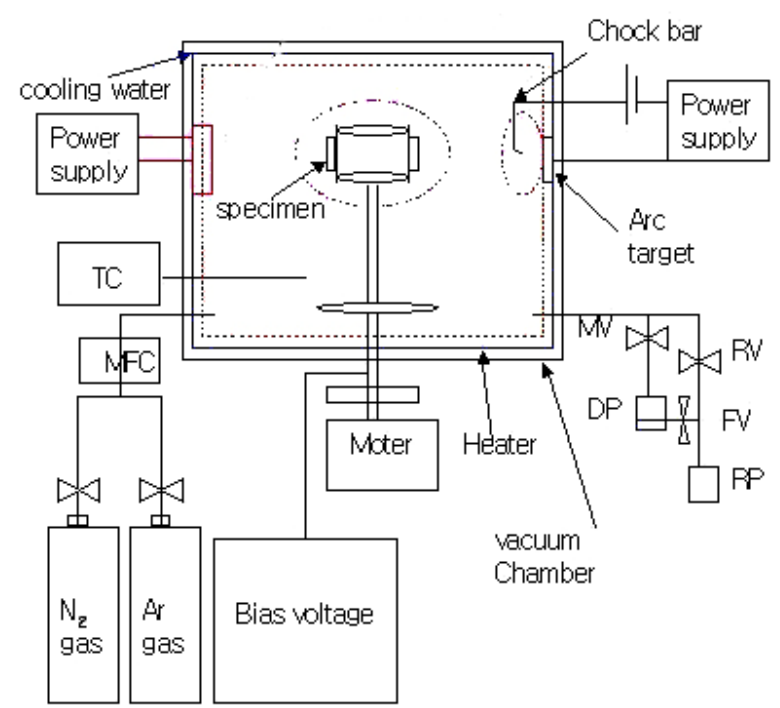

\section{Results and Discussion}

\subsection{Deposition rate of TiAlN films}

The mean effect and percentage contribution to the film thickness for all factors are shown in Figures 2 and 3. For deposition efficiency, the rank is working pressure $(76.62 \%)>$ temperature of substrate $(10.01 \%)>$ bias voltage $(4.83 \%)>$ arc current $(4.49 \%)>$ pre-treatment voltage $(2.37 \%)>$ pre-treatment time $(1.65 \%)$. In our study, it is concluded that the working pressure is the most significant factor, because its percentage contribution is more than $75 \%$. Furthermore, according to the results, the pretreatment voltage and pretreatment time have not any evident influence on the deposition efficiency in arc ion plating. If only the deposition efficiency is considered, the gas pressure during deposition should be as high as possible for collisionless metal atom transport. At low pressure, both the electron density and the ion density (the charge neutrality condition) are low. The excellent adhesion strength of the AIP TiAlN films is created largely by high energy ions bombarding the deposited film during deposition. Thus, the consideration for ion bombardment indicates that a higher working pressure is more desirable. However, at higher pressures, ions have more collisions with background gases, and these collisions reduce the ion energy and make ions less effective bombardment to the substrate. Moreover, when the pressure is too high, the ion density gradient is large and the number of ions reaching the substrate decreases. 
Figure 2. Average thickness of No.1 18 samples.

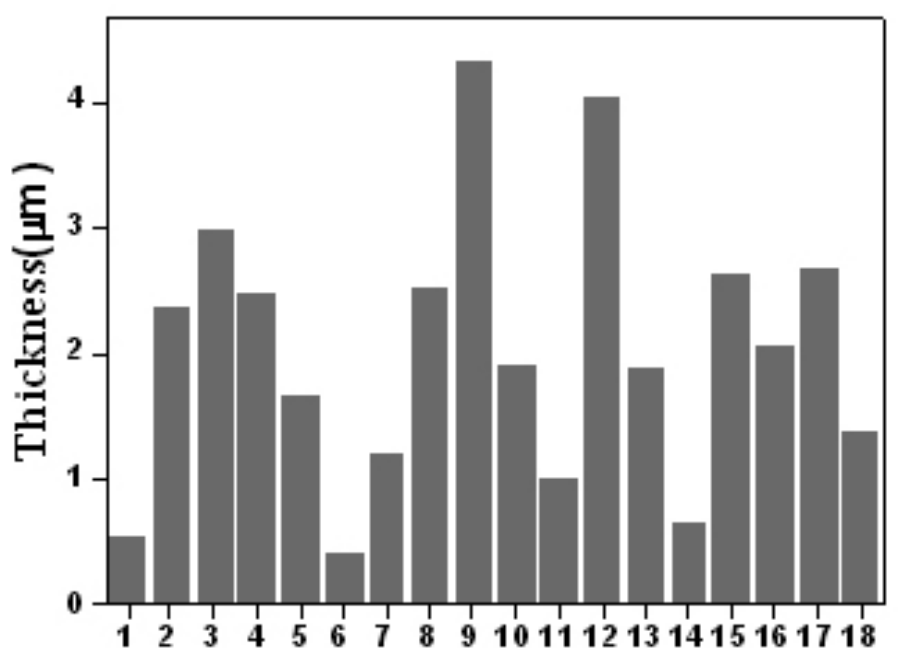

Figure 3. Response graph for the six factors vs. thickness.

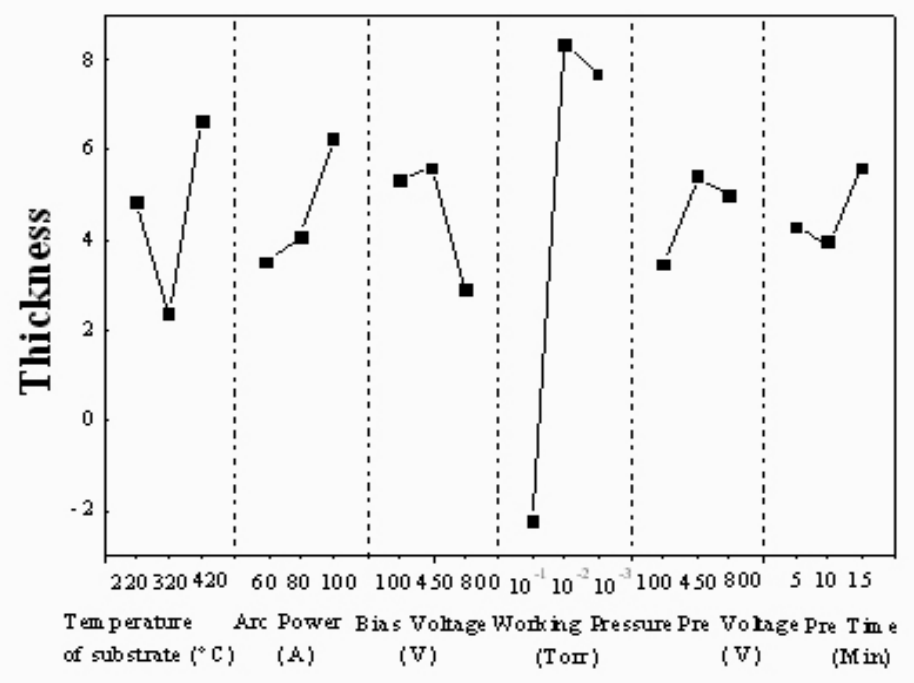

\subsection{Hardness of TiAlN films}

The effect and percentage contribution of hardness for each factor are shown in Figures 4 and 5. For the hardness of the films, the rank of the six factors is working pressure $(36.80 \%)>$ bias voltage $(35.90 \%)>\operatorname{arc}$ current $(18.37 \%)>$ temperature of substrate $(5.53 \%)>$ pretreatment time $(3.29 \%)>$ pretreatment voltage $(0.08 \%)$. This result implies that the most influenced factor for hardness is still the working pressure. It is found that a relatively thicker film is helpful to enhance the hardness of the TiAlN films. As is well known, the intrinsic hardness of surface layers or thin films becomes meaningful only if the influence of the substrate material can be eliminated. It is therefore generally accepted that the limit of depth of the indentation can be as low as about $10 \%$ of the film thickness. Thus, under the same load of $20 \mathrm{mN}$, too low a deposition efficiency resulted in a decrease in the hardness of the TiAlN films. 
Figure 4. Average hardness of No. 1 18 samples.

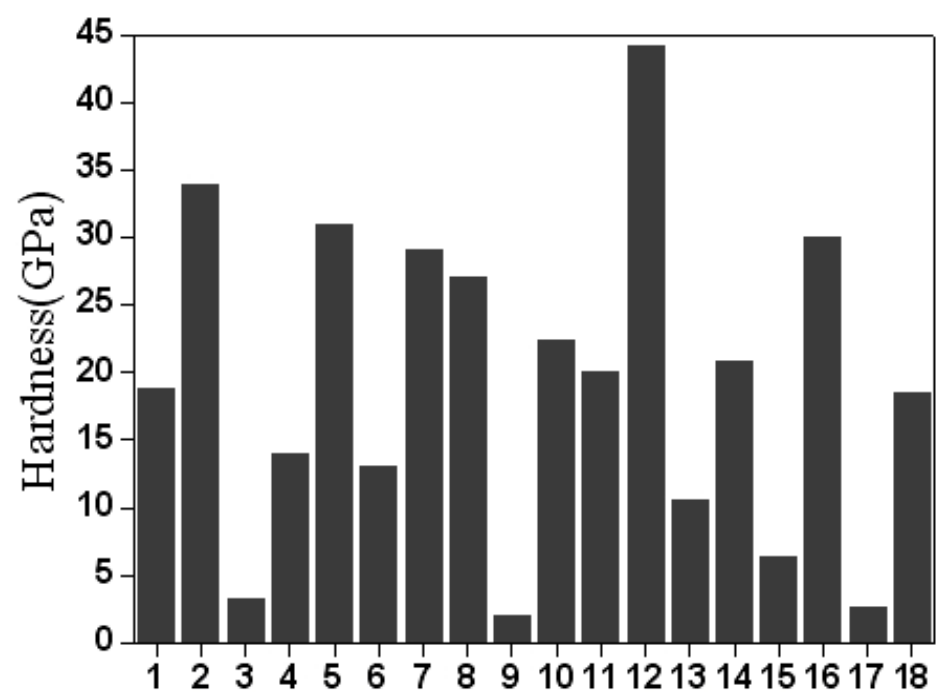

Figure 5. Response graph for the six factors vs. hardness.

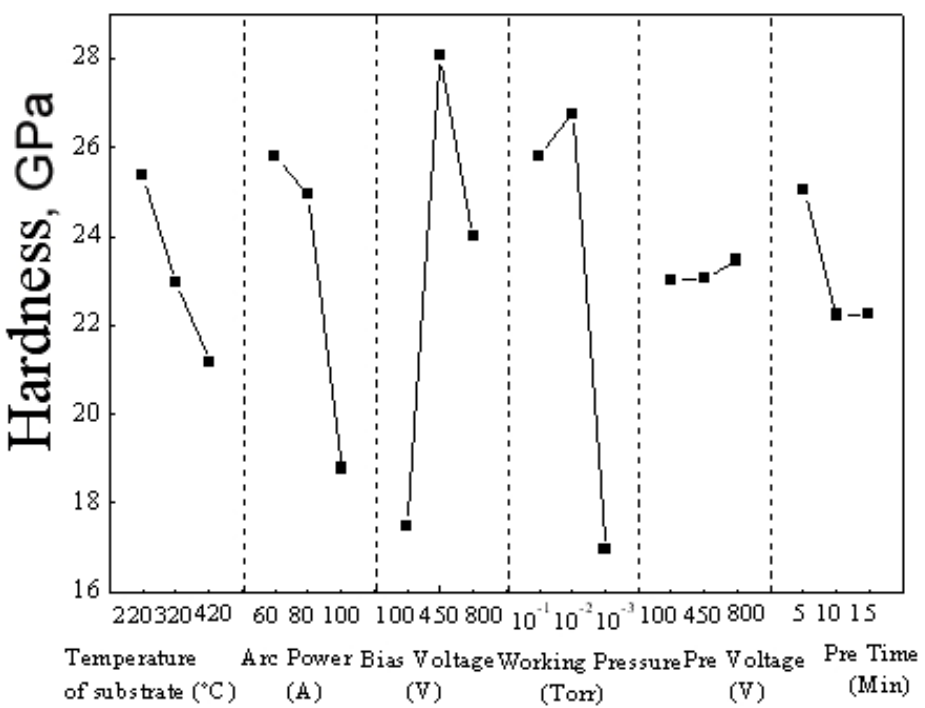

\subsection{The adhesion strength of TiAlN films}

The mean effect and percentage contribution to the adhesion strength for all factors are shown in Figures 6 and 7. The adhesion strength, which ranged from $12.8 \mathrm{~N}$ to $39.0 \mathrm{~N}$, is strongly dependent on the parameters. The influential sequence on critical load is arc current $(30.36 \%)>$ temperature of substrate $(25.04 \%)>$ pretreatment voltage $(15.60 \%)>$ working pressure $(13.67 \%)>$ bias voltage $(11.61 \%)>$ pretreatment time $(3.69 \%)$. The optimized film process which is substrate temperature $220^{\circ} \mathrm{C}$, arc power $60 \mathrm{~A}$, bias voltage $-800 \mathrm{~V}$, nitrogen pressure $10^{-2}$ Torr, pre treated voltage $-450 \mathrm{~V}$ and pretreated time 15 minutes was obtained depending on the rule that the larger the critical load is, the better the adhesion strength is. The critical load of the optimized TiAlN film, which was $53 \mathrm{~N}$, was increased by $43 \%$ compared to the film with the highest critical load before optimization. 
Figure 6. Critical load of No. 1 18 samples.

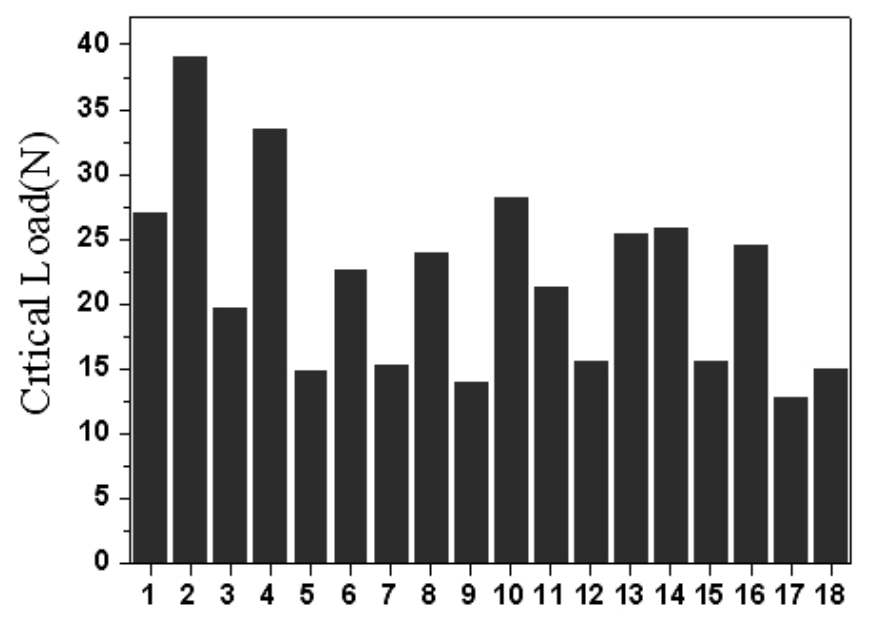

Figure 7. Response graph for the six factors vs. critical load of the scratch test.

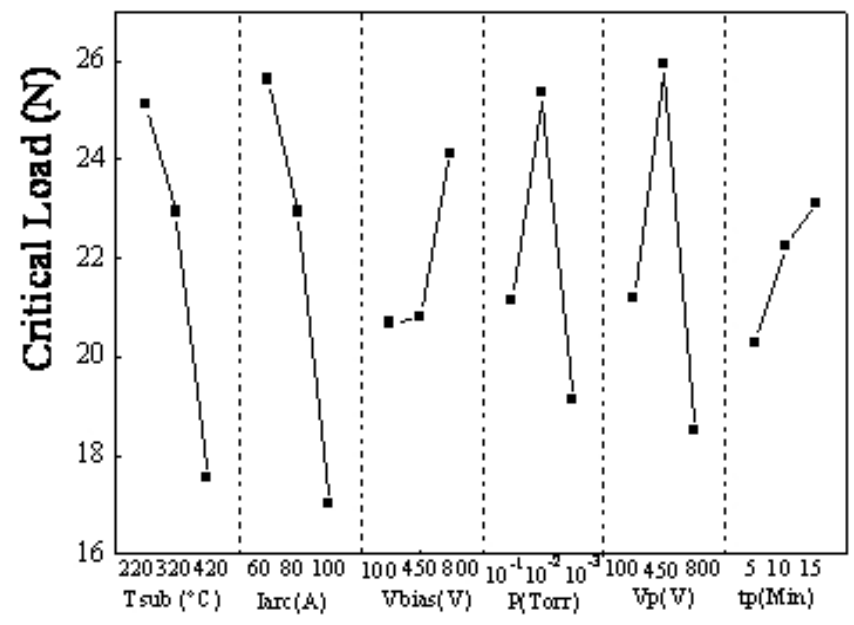

\subsection{Effects of deposition rate, hardness and structure of TiAlN films on adhesion strength}

Figure 8 shows cross-sectional images of TiAlN films with the smallest and largest adhesion strength, corresponding to bias voltages of $-100 \mathrm{~V}$ and $-800 \mathrm{~V}$, respectively. The thicknesses of the TiAlN films with the smallest and largest adhesion strength are $2.68 \mu \mathrm{m}$ and $2.36 \mu \mathrm{m}$, respectively. This indicates that the deposition rate $(39.3 \sim 44.7 \mathrm{~nm} / \mathrm{min})$ has no direct influence on the adhesion strength of the AIP TiAlN films. From the comparison for hardness of the both TiAlN films with the lowest and largest adhesion strength, as observed in Figure 4, the TiAlN films with the lowest and largest adhesion strength possess hardnesses of $4 \mathrm{GPa}$ and $34 \mathrm{GPa}$, respectively. As we know, the microhardness of ternary alloy film such as Ti-Al-N, Cr-Si-N, Ti-Si-N and Cr-Al-N can be increased by residual compressive stresses [13]. Therefore, this is in good agreement with the results reported by Li et al. that an improved film adhesion strength resulted from the internal stress changes from tensile 
stress to compressive stress as the bias voltage increases from $-100 \mathrm{~V}$ to $-800 \mathrm{~V}$, enhancing crystallization [14].

Figure 8. Cross sections of TiAlN layers. a) The smallest adhesion, b) The largest adhesion.



Figure 9 is a comparison of the XRD patterns between the largest and smallest adhesion strength films. The results show that $(\mathrm{Ti}, \mathrm{Al}) \mathrm{N}$ and $\mathrm{Al}$ phases existed in both films. In the film with the lowest adhesion strength, the film is mainly grown with a preferred (111) orientation of the (Ti, Al) N phase. However, in the film with the largest adhesion, the film is grown by (111), (200) and (220) orientations. The films of the lowest and the highest adhesion strength possess $-100 \mathrm{~V}$ and $-800 \mathrm{~V}$ bias voltages, respectively. Thus, the mobility of atoms decrease with the increase of nitrogen flow rates and the lattice plane with higher surface energy, i.e. (200), could favor the growth of crystals at the expense of others [15].

Figure 9. XRD of TiAlN films a) The smallest adhesion, b) The largest adhesion.

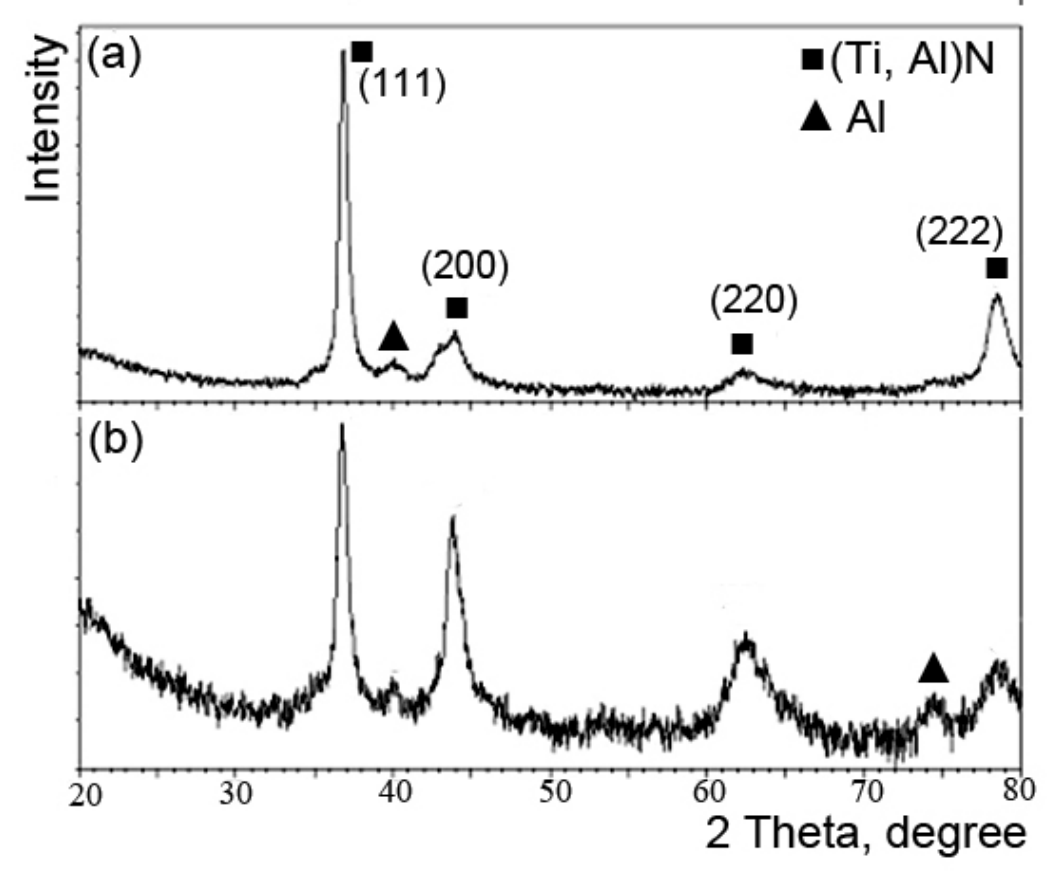


The scratch test results for the two films with the smallest and the largest adhesion strength are shown in Figure 10. It is concluded that the critical load of the largest adhesion $(39.0 \mathrm{~N})$ is three times higher compared with the smallest adhesion $(12.8 \mathrm{~N})$. The frictional forces and AE signals were monitored with increasing loads. The location of critical load is determined by the transition of $\mathrm{AE}$ signals. This is confirmed by frictional forces and an optical microscope because AE signals are more sensitive than the frictional forces, which shows the transition a little bit later. The progressive load scratch tests were performed on each sample [16]. Figure 11 shows SEM images of scratch traces of TiAlN films with the smallest adhesion and the largest adhesion. It is observed that compared to the TiAlN film with the smallest adhesion (Figure 11a), the scratch trace is lower and narrower in the film with the largest adhesion (Figure 11b).

Figure 10. Friction behavior and critical load for progressive load scratch test of TiAlN films: a) The smallest adhesion, b) The largest adhesion.
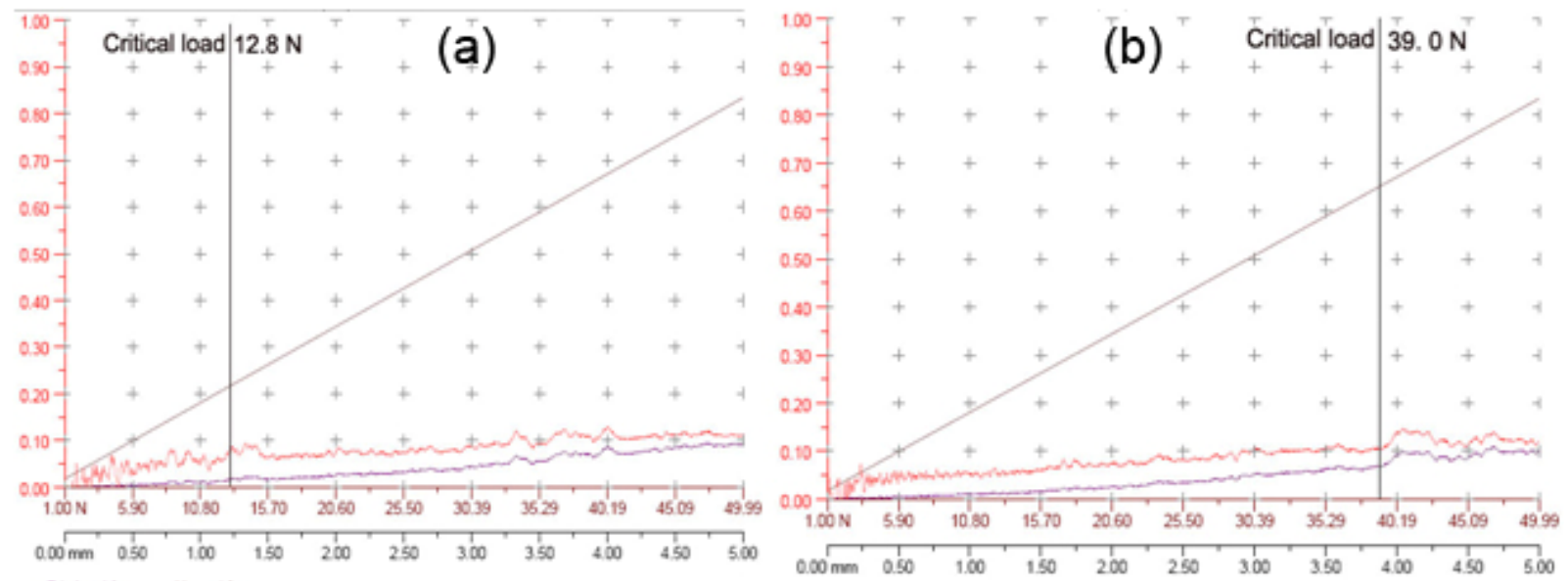

Figure 11. SEM images of scratch traces of TiAlN films: a) The smallest adhesion, b) The largest adhesion.

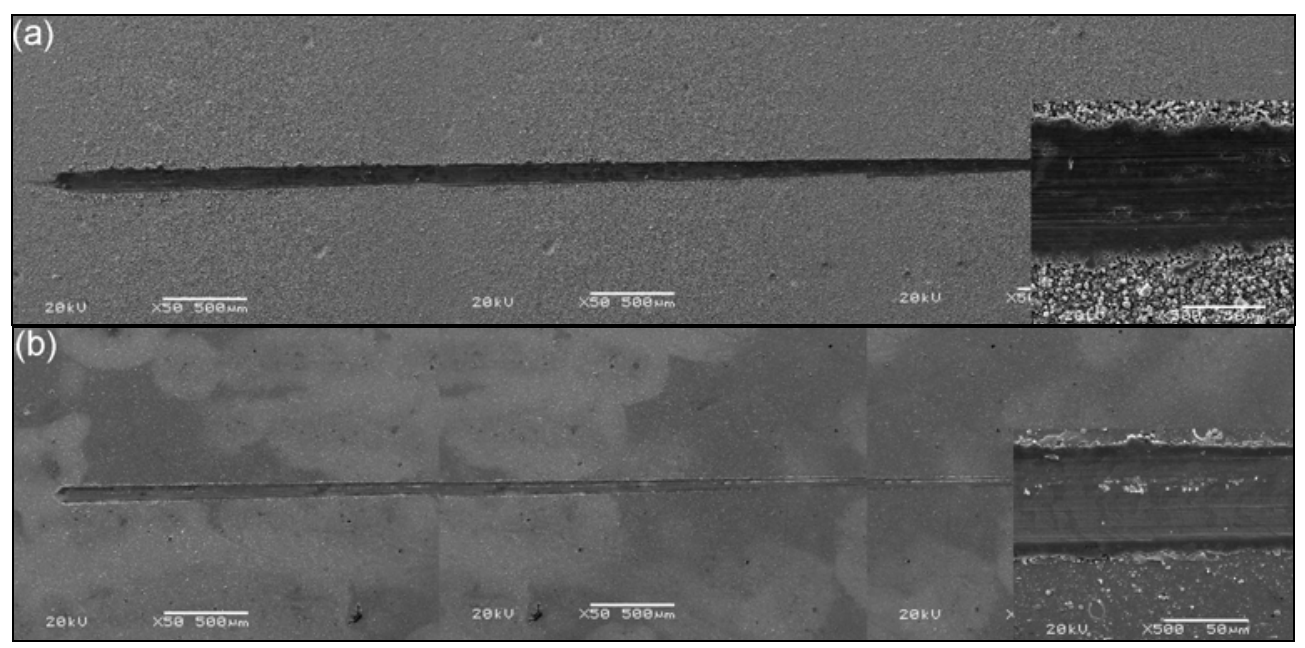




\section{Conclusions}

By applying Taguchi method, the deposition rate, hardness and adhesion strength of AIP TiAlN films were investigated. The optimized process of adhesion strength was substrate temperature $220{ }^{\circ} \mathrm{C}$, arc power $60 \mathrm{~A}$, bias voltage $-800 \mathrm{~V}$, nitrogen pressure $10^{-2}$ Torr, pretreated voltage $-450 \mathrm{~V}$ and pretreatment time 15 minutes. The critical load of optimized TiAlN film $(53 \mathrm{~N})$ increased by $43 \%$ compared to the film with the highest critical load before optimization. The deposition rate had no direct influence on the adhesion strength of the AIP TiAlN films. But for mean hardness of TiAlN film, there was a great difference between the TiAlN films with the lowest (4 GPa) and the largest adhesion strength (34 GPa). The growth of TiAlN films with the lowest and the largest adhesion strength changed from a preferred (111) orientation of (Ti, Al) N phase to competitive (111), (200) and (220) orientations. As a result, the improvement on the adhesion strength of films was attributed to the enhancement of hardness and the emulative growth of (111), (200) and (220) orientations in the film.

\section{Acknowledgements}

This research was supported by "The Korea Research Foundation Grant” (KRF-2006-005-J02701).

\section{References}

1. Kang, G.H.; Uchida, H.; Hoh, E.S. A study on the surface structure of Ti cathode and the macroparticle of TiN films prepared by the arc ion plating process. Surf. Coat. Technol. 1996, 86-87, 421-424.

2. Ljungcrantz, H.; Hultman, L.; Sundgren, J.E. Microstructural investigation of droplets in arcevaporated TiN films. Surf. Coat. Technol. 1994, 63, 123-128.

3. Akari, K.; Tamagaki, H.; Kumakiri, T.; Tsuji, K.; Koh, E.S.; Tai, C.N. Reduction in macroparticles during the deposition of TiN films prepared by arc ion plating. Surf. Coat. Technol. 1990, 43-44, 312-323.

4. Kang, M.C.; Park, I.W.; Kim, K.H. Performance evaluation of AIP-TiAlN coated tool for high speed machining. Surf. Coat. Technol. 2003, 163-164, 734-738.

5. Yoon, S.Y.; Lee, K.O; Kang, S.S.; Kim, K.H. Comparison for mechanical properties between TiN and TiAlN coating layers by AIP technique. J. Mater. Process. Technol. 2002, 130-131, 260-265.

6. Tan, A.H.; Cheng, Y.C. Optimization of wear-corrosion properties of a-C: N films using filtered cathodic arc deposition. Diam. Relat. Mater. 2008, 17, 36-42.

7. Kalita, G.; Adhikari, S.; Aryal, H.R.; Somani, P.R.; Somani, S.P.; Sharon, M.; Umeno, M. Taguchi optimization of device parameters for fullerene and Poly (3-octylthiophene) based heterojunction photovoltaic devices. Diam. Relat. Mater. 2008, 17, 799-803.

8. Ting, J.H.; Chang, C.C.; Chen, S.L.; Lu, D.S.; Kung, C.Y.; Huang, F.Y. Optimization of field emission properties of carbon nanotubes by Taguchi method. Thin Solid Films 2006, 496, 299305. 
9. Gilles, S.; Bourhila, N.; Ikeda, S.; Bernard, C.; Madar, R. Deposition of (Ti, Al) N thin films by organometallic chemical vapor deposition: thermodynarnic predictions and experimental results. Surf. Coat. Thech. 1997, 94-95, 285-290.

10. Burnett, P.J.; Rickerby, D.S. The relationship between hardness and scratch adhession. Thin Solid Films 1987, 154, 403-416.

11. Raveh, A.; Weiss, M.; Pinkas, M.; Rosen, D.Z.; Kimmel, G. Graded Al-AlN, TiN, and TiAlN multilayers deposited by radio-frequency reactive magnetron sputtering. Surf. Coat. Thech. 1999, 114, 269-277.

12. Wang, D.Y.; Chang, C.L.; Wong, K.W.; Li, Y.W.; Ho, W.Y. Improvement of the interfacial integrity of (Ti,Al)N hard coatings deposited on high speed steel cutting tools. Surf. Coat. Thech. 1999, 120-121, 388-394.

13. Wang, Q.; Park, I.W.; Kim, K.H. Influence of $\mathrm{N}_{2}$ gas pressure and negative bias voltage on the microstructure and properties of Cr-Si-N films by a hybrid coating system. J. Vac. Sci. Technol. A 2008, 26, 1188-1194.

14. Li, M.; Wang, F. Effects of nitrogen partial pressure and pulse bias voltage on (Ti, Al) N coatings by arc ion plating. Surf. Coat. Technol. 2003, 167, 197-202.

15. Zhao, S.S.; Du, H.; Zheng, J.D.; Yang, Y.; Wang, W.; Gong, J.; Sun, C. Deposition of thick TiAlN coatings on 2024 Al/SiCp substrate by Arc ion plating. Surf. Coat. Technol. 2008, 202, 5170-5174.

16. Guo, C.T.; Lee, D.; Chen, P.C. Deposition of TiSiN coatings by arc ion plating process. Appl. Surf. Sci. 2008, 254, 3130-3136.

(C) 2009 by the authors; licensee Molecular Diversity Preservation International, Basel, Switzerland. This article is an open-access article distributed under the terms and conditions of the Creative Commons Attribution license (http://creativecommons.org/licenses/by/3.0/). 